doses of tuberculin. It is important also to inject the tuberculin at long intervals.

S. S.

\title{
CORRESPONDENCE
}

\section{FUNCTIONAL SPASM OF ACCOMMODATION}

To the Editor of THE BRITISH JouRnal OF Ophthalmology

SiR,- - In your issue of October Mr. Leslie Paton reports some interesting cases of functional spasm of accommodation.

In a paper on nystagmus, published in the British Medical Journal for November 1, 1913, I reported a case of spasm of accommodation associated with nystagmus. The patient was a young woman, a photographer's re-toucher, whose eyes had been troublesome for a year, and who complained of diplopia. Subjective testing and retinoscopy showed that she had 4D. of myopia. Under atropin her static refraction was low hypermetropia, say, 1D. After she had been under observation for about two months she had an attack of diphtheria, which imposed on her nearly two months' of forced quiescence. On examining her thereafter, I found that all her eye? troubles had disappeared. This case and Mr. Paton's cases, in my opinion, belong to the same category. $\quad$ Yours, etc.,

The LORD DERBY WaR Hospital,

October, 1917. WARRINGTON.

J. A. Wilson.

DEAR SIR,-Having seen the account of some cases of spasm of accommodation, published by Mr. Paton in the BRITISH JOURNAL OF OPHTHALMOLOGY for October, I am sending you a few notes of a case which was in this Hospital under the care of Capt. J. Herbert Parsons.

Admitted Aug. 26, 1917 (a Newfoundlander). Medical card from France headed "Eyes gassed." Not seen by me on admission. Note on case sheet: "Slight conjunctivitis in both eyes ; photophobia, V. under atropine, $\frac{6}{60}$ myopia in L. eye."

Sept. 13 (seen by myself). Still photophobia, but very little flushing. I think photophobia functional.

$$
\text { R.V. } \frac{5}{36} \quad \frac{-4.5}{\mid-4.5}
$$

Sept. 18. When reading type letters disappear; appear again -? functional. 
Sept. 19. R.V. $=\frac{5}{18}$ No $\mathrm{Hm}$.

L.V. $=\frac{5}{18}$ No Hm. $\frac{\mid-4.0}{\mid-4.0}-3.0$ sph. $=\frac{5}{12}$ pt.

Shadows change in a very marked manner; with a plane mirror sometimes definitely against, sometimes definitely with.

Homatropin and cocain in oil (two applications each eye) refracted two hours later :

$$
\begin{aligned}
& \text { R. } \frac{\mid+0.5}{\mid+0.5}+0.75 \text { sph. }=\frac{5}{18} 3 \text { letters } \\
& \text { L. } \frac{\mid+0.5}{\mid+0.5}+1.0 \text { sph. }=\frac{5}{18}
\end{aligned}
$$

Looking into distance at 5 metres each eye converges at times. Fixes with R. for preference; fixes with R. for near. L. eye moves on covering R. On occasions no apparent deviation. (Not having realised the interest of the case, I regret that I did not test for binocular vision.)

At 5 metres without mydriatic $4^{\circ}$ esophoria.

At 5 metres under homatropin and cocain mydriatic $6^{\circ}-9^{\circ}$ esophoria,

Sept. 20.

$$
\begin{array}{r}
\text { R.V. }=\frac{5}{12}-3.0 \text { sph. }=\frac{5}{6} \text { pt. } \\
\text { L.V. }=\frac{5}{9} \text { pt. }-2.5 \text { sph. }=\frac{5}{6} \text { pt. }
\end{array}
$$

Given 1 per cent. atropin drops twice a day for six days.

Sept. 28.

$$
\begin{array}{l|l}
\text { R. } \frac{\mid+1 \cdot 0}{+1 \cdot 0}+1.5 \mathrm{sph} .=\frac{5}{6} \text { easily. } \\
\text { L. } \frac{\mid+1 \cdot 0}{+1 \cdot 0}+1.25 \mathrm{sph} .=\frac{5}{6} \text { easily. }
\end{array}
$$

Media clear, no pathological changes in fundi. Diagnosed as a case of spasm of accommodation with a degree of "functional " loss of acuity of vision on certain occasions.

I hope these notes may be of some interest to you.

Yours, etc.,

$$
\text { J. W. JOYNT }
$$

Civilian Surgeon.

3rd London General Hospital (T.F.),

WANDSWORTH, S.W.,

November 9, 1917. 